\title{
Comparison between Early-Onset and Late-Onset Alzheimer's Disease Patients with Amnestic Presentation: CSF and ${ }^{18}$ F-FDG PET Study
}

\author{
Agostino Chiaravalloti ${ }^{b}$ Giacomo Koch ${ }^{c}$ Sofia Toniolo ${ }^{a}$ Lorena Belli $^{a}$ \\ Francesco Di Lorenzo ${ }^{a}$ Sara Gaudenzic OrazioSchillacib, e

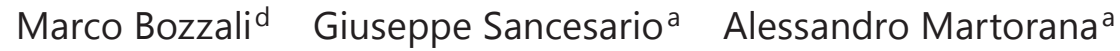 \\ Departments of a System Medicine and ${ }^{b}$ Biomedicine and Prevention, University of Rome \\ Tor Vergata, ' Non-Invasive Brain Stimulation Unit, Department of Behavioural and \\ Clinical Neurology, and d Neuroimaging Laboratory, IRCCS Santa Lucia Foundation, Rome,

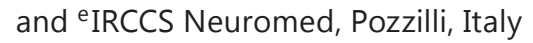

Key Words

Alzheimer's disease · Early onset · Late onset · Precuneus · Cerebrospinal fluid biomarkers

\section{Abstract}

Background/Aims: To investigate the differences in brain glucose consumption between patients with early onset of Alzheimer's disease (EOAD, aged $\leq 65$ years) and patients with late onset of Alzheimer's disease (LOAD, aged >65 years). Methods: Differences in brain glucose consumption between the groups have been evaluated by means of Statistical Parametric Mapping version 8, with the use of age, sex, Mini-Mental State Examination and cerebrospinal fluid values of $A \beta_{1-42}$, phosphorylated Tau and total Tau as covariates in the comparison between EOAD and LOAD. Results: As compared to LOAD, EOAD patients showed a significant decrease in glucose consumption in a wide portion of the left parietal lobe (BA7, BA31 and BA40). No significant differences were obtained when subtracting the EOAD from the LOAD group. Conclusions: The results of our study show that patients with EOAD show a different metabolic pattern as compared to those with LOAD that mainly involves the left parietal lobe. 


\section{Introduction}

Alzheimer's disease (AD) is a neurodegenerative disorder responsible for progressive cognitive decline and dementia [1,2]. Although it is generally defined as an age-related disorder, cases with early onset are described $[3,4]$. These cases represent the early-onset $\mathrm{AD}$ (EOAD) group and are defined by a clinical onset of AD before the age of 65 years. EOAD cases are both familial and sporadic and represent about $10 \%$ of all $\mathrm{AD}$ cases. EOAD can manifest clinically with nonamnestic symptoms in $25-65 \%$ of cases, presenting with language deficits, apraxia and visuospatial functional deficits $[5,6]$. Such a presentation often overlaps with frontotemporal degeneration syndromes or with psychiatric conditions, causing great diagnostic delay $[7,8]$. Although neuropathological studies showed that EOAD and LOAD have the same features and represent a continuum of the same pathological process, differences between EOAD and LOAD are reported $[9,10]$. Indeed, EOAD patients often present (in about half of the cases described in the literature) with atypical neuropsychological symptoms and have an atypical MRI and ${ }^{18} \mathrm{~F}$-FDG PET imaging pattern, with cortical thickness atrophy and hypometabolism, respectively, of the mesial temporal and parietal lobes (i.e. precuneus, lateral parietal and occipital brain regions) with relative hippocampal sparing, with respect to LOAD, where hippocampi are more involved; in addition, EOAD patients tend to have a more aggressive rate of progression with a shorter duration of the disease than LOAD patients [11-13]. These observations led us to suppose that EOAD might represent a definite clinicopathological entity, characterized by distinct pathophysiological mechanisms and pathological burden responsible for a faster decline as well as for atypical presentation. Several recent studies have investigated cerebrospinal fluid (CSF) biomarkers of EOAD, focusing on atypical presentations, with controversial results [14]. Although differences do not reach statistical significance, EOAD individuals often show lower CSF $A \beta_{42}$ and very high total Tau ( $\mathrm{t}$-Tau) levels, features that are compatible with faster cognitive decline in $\mathrm{AD}$. $\left[{ }^{11} \mathrm{C}\right]$-labeled Pittsburgh compound B studies showed greater $A \beta$ accumulation in posterior cortical areas, indicating a possible vulnerability in these individuals for these regions $[15,16]$. However, most of the available data uniquely describe EOAD with atypical presentation, and the radiological and laboratory findings presented in the literature often reflect the asymmetric and focal localization features of EOAD. Data on the amnestic presentation of EOAD are, to our knowledge, not available. Here, we present a CSF analysis and an ${ }^{18} \mathrm{~F}-\mathrm{FDG}$ PET study of a subgroup of EOAD patients with a typical amnestic presentation and compare them with a group of LOAD patients with an amnestic presentation.

\section{Materials and Methods}

\section{Patients}

We examined a total of 84 patients with a diagnosis of probable AD according to the NINCDS-ADRDA criteria [17]. The mean age $( \pm S D)$ of the patients was $69( \pm 7)$ years. Based on the age at onset, the patients could be divided into an EOAD ( $\leq 65$ years of age) and an LOAD ( $>65$ years of age) group. The EOAD group consisted of 23 patients, with a mean age of $64( \pm 2)$ years, while 65 patients were in the LOAD group, with a mean age of $76( \pm 3)$ years. All patients underwent a complete clinical investigation, including a medical history, neurological examination, Mini-Mental State Examination (MMSE), a complete blood screening (including routine examinations, thyroid hormones, level of vitamin $\mathrm{B}_{12}$ ), a neuropsychological examination [18], a complete neuropsychiatric evaluation and neuroimaging consisting of magnetic resonance imaging (1.5-tesla MRI). Exclusion criteria were the following: patients with isolated deficits and/or unmodified MMSE $(\geq 25 / 30)$ on revisit $(6$, 
Table 1. Outline of the AD population examined

\begin{tabular}{lcccc}
\hline & Population $(\mathrm{n}=84)$ & $\mathrm{U65}(\mathrm{n}=23)$ & O65 $(\mathrm{n}=61)$ & $\mathrm{p}$ value \\
\hline Mean age \pm SD, years & \multicolumn{1}{c}{$69 \pm 7$} & $60.5 \pm 2$ & $76 \pm 3$ & $<0.01$ \\
MMSE score & $18.52 \pm 6.481$ & $18.18 \pm 7.292$ & $18.65 \pm 6.209$ & 0.5466 \\
$\mathrm{t}-\mathrm{Tau}, \mathrm{pg} / \mathrm{ml}$ & $678.8 \pm 322.5$ & $768.9 \pm 363$ & $644.9 \pm 302.2$ & 0.1118 \\
$\mathrm{p}-\mathrm{Tau}, \mathrm{pg} / \mathrm{ml}$ & $81.29 \pm 47.19$ & $82.70 \pm 34.56$ & $80.75 \pm 51.40$ & 0.2831 \\
$\mathrm{~A} \beta_{1-42, \mathrm{pg} / \mathrm{ml}}$ & $321.2 \pm 127.1$ & $300.5 \pm 133$ & $329.0 \pm 125$ & 0.4281 \\
\hline
\end{tabular}

Table 2. Neuropsychological evaluation of the EOAD and LOAD groups

\begin{tabular}{lrrl}
\hline & EOAD & LOAD & $\mathrm{p}$ \\
\hline MMSE score & $18.9 \pm 1.3$ & $19.2 \pm 0.7$ & n.s. \\
Rey Auditory Verbal Learning Test, immediate recall & $15.9 \pm 1.6$ & $22.5 \pm 0.9$ & 0.0032 \\
Rey Auditory Verbal Learning Test, delayed recall & $1.57 \pm 0.4$ & $2.19 \pm 0.3$ & n.s. \\
Rey Complex Figure Test, copy & $16.35 \pm 2.3$ & $17.52 \pm 1.3$ & n.s. \\
Rey Complex Figure Test, delayed recall & $4.34 \pm 1.1$ & $7.45 \pm 0.7$ & 0.05 \\
Raven's Colored Progressive Matrices & $15.8 \pm 1.4$ & $20.27 \pm 0.7$ & n.s. \\
Phonological Word Fluency Test & $19.47 \pm 2.4$ & $22.15 \pm 1.3$ & n.s. \\
\hline
\end{tabular}

12 and 18 months of follow-up) and patients with clinically manifest acute stroke in the previous 6 months showing a Hachinski scale score $>4$ and radiological evidence of subcortical lesions. None of the patients revealed pyramidal and/or extrapyramidal signs at the neurological examination. At the time of enrolment, in the 30 days before participating in this study, none of the patients had been treated with drugs that might have modulated cerebral cortex excitability, such as antidepressants, or any other neuroactive drugs (i.e. benzodiazepines, antiepileptic drugs or neuroleptics), and they had not been treated with cholinesterase inhibitors.

The study was performed according to the Declaration of Helsinki and was approved by the Ethics Committee of the Tor Vergata University in Rome. All AD patients showed a cognitive profile consistent with mild dementia, as assessed by a neuropsychological evaluation including the MMSE and a standardized neuropsychological battery [19]. On the MMSE, $\mathrm{AD}$ patients scored a mean of $18.5 \pm 6.4$, and the Clinical Dementia Rating score was $1.3 \pm 1.21$. A general overview of the AD population examined is provided in table 1. All participants or their legal guardians gave their written informed consent after receiving extensive information on the study. The Local Ethics Committee approved the study procedures.

Cognitive Evaluation

At the time of enrollment, all recruited patients were administered a neuropsychological battery (table 2) including the following cognitive domains: general cognitive efficiency (MMSE) [20]; verbal episodic long-term memory (Rey Auditory Verbal Learning Test, longterm memory, 15-word list immediate and 15-min delayed recall) [21]; visuospatial abilities and visuospatial episodic long-term memory (Rey Complex Figure Test, copy and 10-min delayed recall) [22]; executive functions (Phonological Word Fluency Test) [19], and analogic reasoning (Raven's Colored Progressive Matrices) [19]. For all tests employed, we used the 
Italian normative data for both score adjustment (gender, age and education) and to define cutoff scores of normality, determined as the lower limit of the $95 \%$ tolerance interval. For each test, normative data are reported in the corresponding references.

\section{CSF Sampling}

In our study, we performed lumbar puncture and CSF sampling to improve the diagnostic accuracy in the AD patients. The first $12 \mathrm{ml}$ of CSF were collected in a polypropylene tube and directly transported to the local laboratory for centrifugation at $2,000 \mathrm{~g}$ at $+4{ }^{\circ} \mathrm{C}$ for $10 \mathrm{~min}$. The supernatant was pipetted off, gently stirred and mixed to avoid potential gradient effects, and aliquoted in 1-ml portions in polypropylene tubes that were stored at $-80^{\circ} \mathrm{C}$ pending biochemical analyses, without being thawed and re-frozen. In the AD patients, CSF t-Tau and phosphorylated Tau ( $p$-Tau, Thr181) concentrations were determined using a sandwich ELISA (Innotest ${ }^{\circledR}$ hTAU-Ag, Innogenetics, Gent, Belgium). CSF A $\beta_{1-42}$ levels were determined using a sandwich ELISA [Innotest $\beta$-amyloid(1-42), Innogenetics] specifically constructed to measure $A \beta$ containing both the first and 42 nd amino acid, as previously described [23].

\section{Control Group}

Fifty-eight chemotherapy-naïve subjects (males, 33; females, 25; mean age, $67 \pm 9$ years) undergoing an ${ }^{18} \mathrm{~F}$-FDG PET/CT and found to be completely negative for various diseases were enrolled in the study and served as the control group (CG), as proposed in other previous studies [24]. Of them, 22 (males, 10; females, 12) were under 65 years old (U65) and 36 (females, 11; males, 25) were over 65 years old (065). Part of them has already been considered in another study published by our group [25]. Before their inclusion in our study, all of them had previously been evaluated for the absence of clinical signs of AD by an experienced neurologist (A.M.), and the MRI, performed $7 \pm 2$ days before PET/CT examination, was negative for brain injury in all of them.

\section{PET/CT Scanning}

The PET/CT system Discovery VCT (GE Medical Systems, Knoxville, Tenn., USA) was used to assess ${ }^{18} \mathrm{~F}$-FDG brain distribution in all patients by means of a 3-dimensional mode standard technique in a $256 \times 256$ matrix. Reconstruction was performed using the 3-dimensional reconstruction method of ordered subset expectation maximization with 20 subsets and with 4 iterations. The system combines a high-speed ultra 16-detector row (912 detectors per row) CT unit and a PET scanner with 13,440 bismuth germanate crystals in 24 rings (axial full width at half maximum 1-cm radius, $5.2 \mathrm{~mm}$ in the 3-dimensional mode, axial field of view $157 \mathrm{~mm}$ ). A low-ampere CT scan of the head for attenuation correction (40 mA; $120 \mathrm{Kv}$ ) was performed before PET image acquisition.

All the subjects had fasted for at least $6 \mathrm{~h}$ before intravenous injection of ${ }^{18} \mathrm{~F}-\mathrm{FDG}$; the dose range administered was 185-210 MBq. After the injection, all the patients lay down in a noiseless and semi-darkened room with their eyes open and without any artificial stimulation. PET/CT acquisition started 30 min after ${ }^{18} \mathrm{~F}$-FDG injection.

Patients and controls with diabetes, psychiatric disorders, a history of oncologic disease, HIV, epilepsy and surgery, radiation or trauma to the brain were excluded from the study. Patients were not taking any medications. Moreover, we excluded from our study all the patients treated with drugs that could interfere with ${ }^{18} \mathrm{~F}-\mathrm{FDG}$ uptake and distribution in the brain [26]. 


\section{Statistical Analysis}

We calculated the mean and SD for age, $\mathrm{p}$-Tau, $\mathrm{t}-\mathrm{Tau}, \mathrm{A} \beta_{1-42}$ amyloid peptide and MMSE. In order to make sure that the values of the main clinical and CSF parameter examined had a Gaussian distribution, D'Agostino's K squared normality test was applied (where the null hypothesis means that the data are normally distributed). Differences in clinical and CSF parameters between EOAD and LOAD and CG subjects were evaluated by means of the MannWhitney U test. Differences in brain ${ }^{18}$ F-FDG uptake were analyzed using Statistical Parametric Mapping (SPM8, Wellcome Department of Cognitive Neurology, London, UK) implemented in MATLAB 2012b (Mathworks, Natick, Mass., USA). PET data were subjected to affine and nonlinear spatial normalization into the Montreal Neurological Institute space. The spatially normalized set of images was then smoothed with an 8-mm isotropic Gaussian filter to blur individual variations in gyral anatomy and to increase the signal-to-noise ratio. Images were globally normalized using proportional scaling to remove confounding effects to global cerebral glucose metabolism changes, with a threshold masking of 0.8 . The resulting statistical parametric maps (SPM $\{\mathrm{t}\}$ ) were transformed into a normal distribution $(\mathrm{SPM}\{\mathrm{z}\})$ unit. Correction of SPM coordinates to match the Talairach coordinates was achieved by the subroutine implemented by Matthew Brett (http://www.mrc-cbu.cam.ac.uk/Imaging). Brodmann areas (BAs) were then identified at a range of $0-3 \mathrm{~mm}$ from the corrected Talairach coordinates of the SPM output isocenters, after having imported them from the Talairach client (http://www.talairach.org/index.html). Thresholds $\leq 0.001$ corrected at cluster level were accepted as significant. Only those clusters containing more than $125(5 \times 5 \times 5$ voxels, i.e. $11 \times 11 \times 11 \mathrm{~mm}$ ) contiguous voxels were accepted as significant, based on the calculation of the partial volume effect resulting from the spatial resolution of the PET camera (about double the full width at half maximum). The following voxel-based comparisons were assessed for AD patients: $L O A D$ versus EOAD and vice versa. As far as the CG is concerned, the following voxel-based comparisons were assessed: 065 versus U65 and vice versa. In the comparison between $\mathrm{AD}$ and CG subjects, the following voxel-based comparisons were assessed: LOAD versus 065 and vice versa, and EOAD versus U65 and vice versa. All the comparisons were performed using a 'two-sample t test' design model.

In the SPM maps, we searched the brain areas with a significant correlation using a statistical threshold of $p=0.001$, familywise error corrected for the problem of multiple comparisons, with an extent threshold of 100 voxels.

With the exception of the comparisons in which a CG was used (in which CSF was not tested), age, sex, MMSE, t-Tau, p-Tau and $A \beta_{1-42}$ were used as covariates in the SPM analyses.

\section{Results}

The values for MMSE, age, $p$-Tau, t-Tau and $A \beta_{1-42}$ amyloid peptide were not normally distributed $(\mathrm{p}<0.001)$. We did not find statistically significant differences when comparing age, $\mathrm{p}$-Tau, t-Tau, $\mathrm{A} \beta_{1-42}$ amyloid peptide and MMSE in EOAD versus LOAD patients. In particular, the results of the comparisons were: $p>0.9$ for MMSE; $p=0.226$ for $\mathrm{t}-\mathrm{Tau} ; \mathrm{p}=$ 0.284 for $\mathrm{p}$-Tau, and $\mathrm{p}=0.429$ for $\mathrm{A} \beta_{1-42}$ amyloid peptide (fig. 1 ).

\section{AD Patients (065 vs. U65 and vice versa)}

As compared to LOAD patients, EOAD patients showed a significant decrease in glucose consumption in a wide portion of the left parietal lobe (BA7, BA31 and BA40). No significant differences were obtained when subtracting the EOAD group from the LOAD group (no increased glucose consumption in the LOAD as compared to the EOAD group). Detailed results are provided in table 3 and figure 2. 


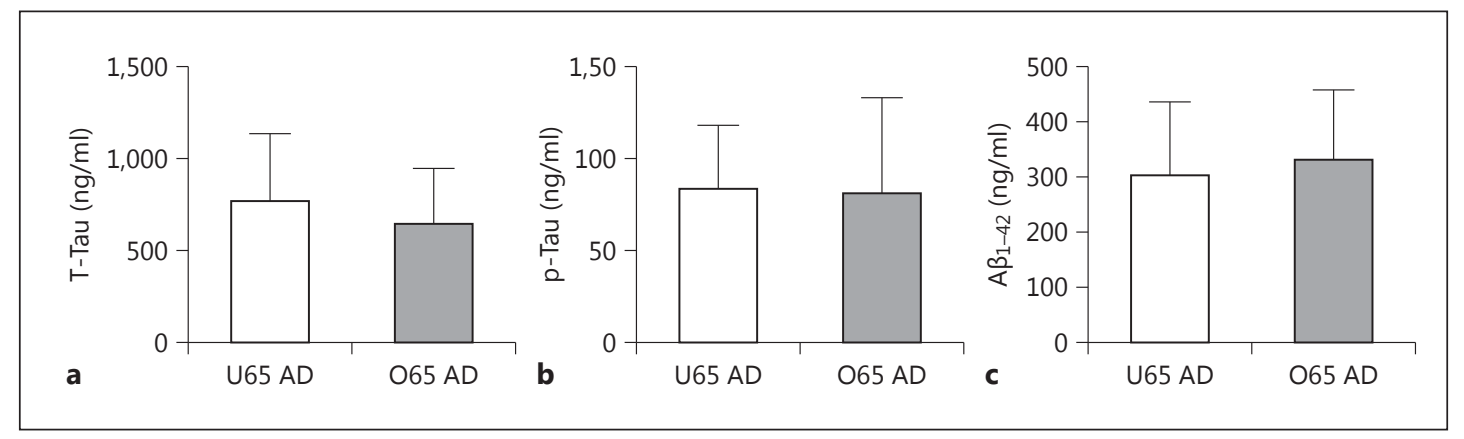

Fig. 1. Box plots of the data in table 1 showing no significant differences in t-Tau (a), p-Tau (b) and $A \beta_{1-42}$ amyloid peptide $(\mathbf{c})$ levels in CSF in LOAD versus EOAD patients.
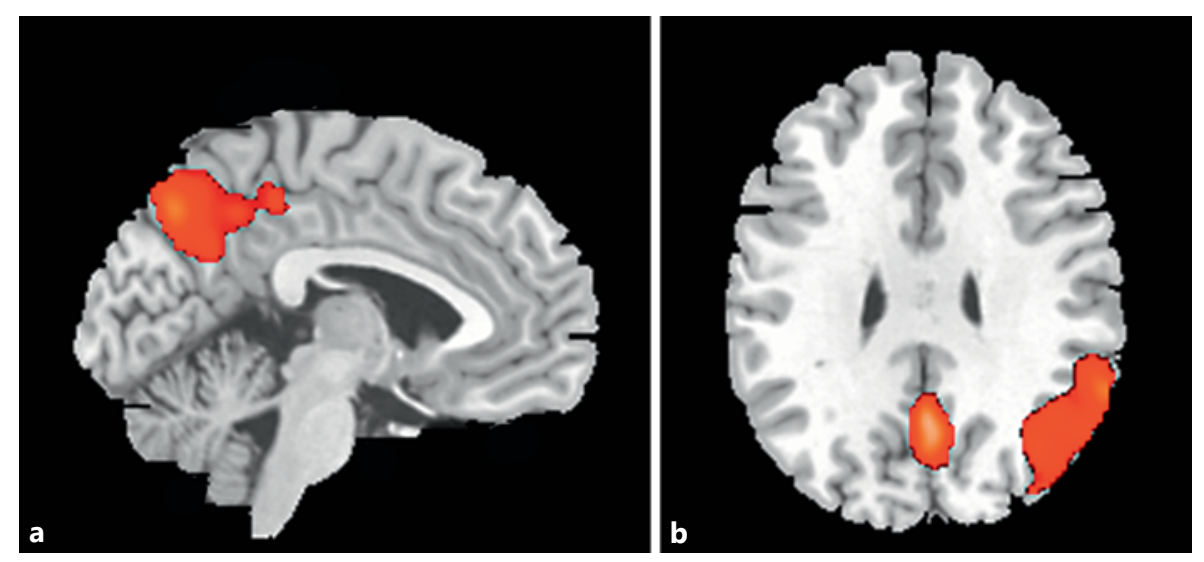

Fig. 2. T1-weighted magnetic resonance superimposition of the data presented in table 2. Comparisons between ${ }^{18}$ F-FDG uptake in LOAD patients $(n=61)$ and that in EOAD patients $(n=23)$ showing a reduction in cortical glucose consumption in the left precuneus (a, sagittal view) and in the left supramarginal gyrus (b, axial view) in the latter group.

Table 3. Numerical results of SPM comparisons between ${ }^{18}$ F-FDG uptake in 065 AD patients $(n=61)$ and U65 AD patients $(\mathrm{n}=23)$

\begin{tabular}{|c|c|c|c|c|c|c|c|c|}
\hline \multirow[t]{2}{*}{ Analysis } & \multicolumn{5}{|l|}{ Cluster level } & \multicolumn{3}{|l|}{ Voxel level } \\
\hline & $\begin{array}{l}\text { cluster p } \\
\text { (FWE-corr) }\end{array}$ & $\begin{array}{l}\text { cluster } \\
\text { p (FDR-corr) }\end{array}$ & $\begin{array}{l}\text { cluster } \\
\text { extent }\end{array}$ & $\begin{array}{l}\text { cortical } \\
\text { region }\end{array}$ & $\begin{array}{l}\mathrm{Z} \text { score of } \\
\text { maximum }\end{array}$ & $\begin{array}{l}\text { Talairach } \\
\text { coordinates }\end{array}$ & cortical region & BA \\
\hline $065-\mathrm{U} 65$ & 0.000 & 0.000 & 14932 & $\begin{array}{l}\text { L parietal } \\
\text { L parietal } \\
\text { L parietal }\end{array}$ & $\begin{array}{l}4.83 \\
4.50 \\
4.38\end{array}$ & $\begin{array}{l}-2,-72,46 \\
-2,-52,30 \\
-60,-48,34\end{array}$ & $\begin{array}{l}\text { Precuneus } \\
\text { Precuneus } \\
\text { Supramarginal } \\
\text { gyrus }\end{array}$ & $\begin{array}{r}7 \\
31 \\
40\end{array}$ \\
\hline U65-065 & - & - & - & - & - & - & - & - \\
\hline
\end{tabular}

In the 'cluster level' section on the left, the number of voxels, the corrected $\mathrm{p}$ value of significance and the cortical region where the voxel is found are all reported for each significant cluster. In the 'voxel level' section, all of the coordinates of the correlation sites (with the Z score of the maximum correlation point), the corresponding cortical region and the BA are reported for each significant cluster. In case the maximum correlation is achieved outside the gray matter, the nearest gray matter (within a range of $5 \mathrm{~mm}$ ) is indicated with the corresponding BA. FWE = Familywise error; FDR = false discovery rate. 
Table 4. Numerical results of SPM comparisons between ${ }^{18}$ F-FDG uptake in 065 CG subjects ( $\mathrm{n}=36$ ) and U65 CG subjects $(\mathrm{n}=22)$

\begin{tabular}{|c|c|c|c|c|c|c|c|c|}
\hline \multirow[t]{2}{*}{ Analysis } & \multicolumn{5}{|l|}{ Cluster level } & \multicolumn{3}{|l|}{ Voxel level } \\
\hline & $\begin{array}{l}\text { cluster } \\
\text { p (FWE-corr) }\end{array}$ & $\begin{array}{l}\text { cluster } \\
\mathrm{p} \text { (FDR-corr) }\end{array}$ & $\begin{array}{l}\text { cluster } \\
\text { extent }\end{array}$ & $\begin{array}{l}\text { cortical } \\
\text { region }\end{array}$ & $\begin{array}{l}\mathrm{Z} \text { score of } \\
\text { maximum }\end{array}$ & $\begin{array}{l}\text { Talairach } \\
\text { coordinates }\end{array}$ & cortical region & $\mathrm{BA}$ \\
\hline U65 - 065 & 0.000 & 0.000 & 2683 & $\begin{array}{l}\text { R limbic } \\
\text { R limbic }\end{array}$ & $\begin{array}{l}5.84 \\
4.50\end{array}$ & $\begin{array}{c}2,30,22 \\
-2,-52,30\end{array}$ & $\begin{array}{l}\text { Anterior cingulate } \\
\text { Cingulate gyrus }\end{array}$ & $\begin{array}{l}24 \\
32\end{array}$ \\
\hline $065-\mathrm{U} 65$ & - & - & - & - & - & - & - & - \\
\hline
\end{tabular}

In the 'cluster level' section on the left, the number of voxels, the corrected p value of significance and the cortical region where the voxel is found are all reported for each significant cluster. In the 'voxel level' section, all of the coordinates of the correlation sites (with the $\mathrm{Z}$ score of the maximum correlation point), the corresponding cortical region and the BA are reported for each significant cluster. In the case that the maximum correlation is achieved outside the gray matter, the nearest gray matter (within a range of $5 \mathrm{~mm}$ ) is indicated with the corresponding BA. FWE = Familywise error; FDR = false discovery rate.

Fig. 3. T1-weighted magnetic resonance superimposition of the CG data presented in table 2. Comparisons between ${ }^{18} \mathrm{~F}$-FDG uptake in 065 CG subjects $(n=36)$ and that in U65 CG subjects $(n=22)$ showing a reduction in cortical glucose consumption in the left anterior cingulate cortex in 065 as compared to U65 subjects.

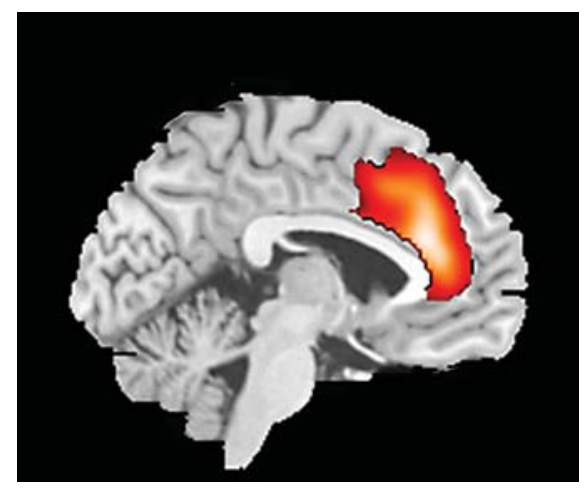

CG Subjects (065 vs. U65 and vice versa)

As compared to 065 subjects, U65 subjects did not show any area of decreased glucose consumption. As compared to U65 subjects, 065 subjects showed a reduced glucose consumption in the right cingulate cortex (BA24 and BA32). Detailed results are provided in table 4 and figure 3.

\section{AD versus CG Subjects}

As compared to CG subjects with a similar age, LOAD patients showed a significant reduction in glucose consumption in a wide portion of the right parietal lobe (BA7) and the left temporal lobe (BA20 and BA37). No significant differences were obtained when subtracting the 065 LOAD subjects from the LOAD group. As compared to CG subjects with a similar age, the EOAD group showed a significant reduction in glucose consumption in a wide portion of the right parietal lobe (BA7). No significant differences were obtained when subtracting the U65 from the EOAD subjects. Detailed results are provided in tables 5 and 6.

\section{Discussion}

In the early phases, $\mathrm{AD}$ is mainly characterized by memory dysfunction, except for cases with early onset that present with an atypical neuropsychological profile. Most of the available literature focused on these cases with a typical presentation, describing their neuropsycho- 
Chiaravalloti et al.: Comparison between Early-Onset and Late-Onset Alzheimer's

Disease Patients with Amnestic Presentation: CSF and ${ }^{18}$ F-FDG PET Study

Table 5. Numerical results of SPM comparisons between ${ }^{18}$ F-FDG uptake in 065 AD patients $(n=61)$ and 065 CG subjects $(\mathrm{n}=36)$

\begin{tabular}{|c|c|c|c|c|c|c|c|c|}
\hline \multirow[t]{2}{*}{ Analysis } & \multicolumn{5}{|l|}{ Cluster level } & \multicolumn{3}{|l|}{ Voxel level } \\
\hline & $\begin{array}{l}\text { cluster } \\
\text { p (FWE-corr) }\end{array}$ & $\begin{array}{l}\text { cluster } \\
\text { p (FDR-corr) }\end{array}$ & $\begin{array}{l}\text { cluster } \\
\text { extent }\end{array}$ & $\begin{array}{l}\text { cortical } \\
\text { region }\end{array}$ & $\begin{array}{l}\mathrm{Z} \text { score of } \\
\text { maximum }\end{array}$ & $\begin{array}{l}\text { Talairach } \\
\text { coordinates }\end{array}$ & cortical region & $\mathrm{BA}$ \\
\hline \multirow[t]{5}{*}{$065 \mathrm{CG}-065 \mathrm{AD}$} & 0.000 & 0.000 & 12182 & $\mathrm{R}$ parietal & 7.22 & $12,-58,36$ & Precuneus & 7 \\
\hline & & & & $\mathrm{R}$ parietal & 6.95 & $10,-52,36$ & Precuneus & 7 \\
\hline & & & & R parietal & 6.68 & $4,-72,36$ & Precuneus & 7 \\
\hline & 0.012 & 0.009 & 14460 & L temporal & 5.58 & $-60,-36,-20$ & $\begin{array}{l}\text { Inferior temporal } \\
\text { gyrus }\end{array}$ & 120 \\
\hline & & & & L temporal & 3.24 & $-44,-56,-12$ & Fusiform gyrus & 37 \\
\hline 065 AD - 065 CG & - & - & - & - & - & - & - & - \\
\hline
\end{tabular}

In the 'cluster level' section on the left, the number of voxels, the corrected p value of significance and the cortical region where the voxel is found are all reported for each significant cluster. In the 'voxel level' section, all of the coordinates of the correlation sites (with the $\mathrm{Z}$ score of the maximum correlation point), the corresponding cortical region and the BA are reported for each significant cluster. In case the maximum correlation is achieved outside the gray matter, the nearest gray matter (within a range of $5 \mathrm{~mm}$ ) is indicated with the corresponding BA. FWE = Familywise error; FDR = false discovery rate.

Table 6. Numerical results of SPM comparisons between ${ }^{18}$ F-FDG uptake in U65 AD patients $(n=23)$ and U65 CG subjects $(\mathrm{n}=22)$

\begin{tabular}{|c|c|c|c|c|c|c|c|c|}
\hline \multirow[t]{2}{*}{ Analysis } & \multicolumn{5}{|l|}{ Cluster level } & \multicolumn{3}{|l|}{ Voxel level } \\
\hline & $\begin{array}{l}\text { cluster } \\
\text { p (FWE-corr) }\end{array}$ & $\begin{array}{l}\text { cluster } \\
\text { p (FDR-corr) }\end{array}$ & $\begin{array}{l}\text { cluster } \\
\text { extent }\end{array}$ & $\begin{array}{l}\text { cortical } \\
\text { region }\end{array}$ & $\begin{array}{l}\mathrm{Z} \text { score of } \\
\text { maximum }\end{array}$ & $\begin{array}{l}\text { Talairach } \\
\text { coordinates }\end{array}$ & $\begin{array}{l}\text { cortical } \\
\text { region }\end{array}$ & $\mathrm{BA}$ \\
\hline \multirow[t]{2}{*}{ U65 CG - U65 AD } & \multirow[t]{2}{*}{0.000} & \multirow[t]{2}{*}{0.000} & \multirow[t]{2}{*}{22089} & $\mathrm{R}$ parietal & 7.93 & $42,-62,50$ & Precuneus & 7 \\
\hline & & & & $\mathrm{R}$ parietal & 7.75 & $42,-76,42$ & Precuneus & 19 \\
\hline U65 AD - U65 CG & - & - & - & - & - & - & - & - \\
\hline
\end{tabular}

In the 'cluster level' section on the left, the number of voxels, the corrected p value of significance and the cortical region where the voxel is found are all reported for each significant cluster. In the 'voxel level' section, all of the coordinates of the correlation sites (with the Z score of the maximum correlation point), the corresponding cortical region and the BA are reported for each significant cluster. In case the maximum correlation is achieved outside the gray matter, the nearest gray matter (within a range of $5 \mathrm{~mm}$ ) is indicated with the corresponding BA. FWE = Familywise error; FDR = false discovery rate.

logical, biomarker (CSF/PET) and MRI profiles. Here, we studied CSF and ${ }^{18}$ F-FDG PET differences between the EOAD and LOAD groups with a typical amnestic presentation. Our results show that EOAD patients with an amnestic presentation show features comparable to those observed in the EOAD group with an atypical presentation, and, moreover, confirm the finding that EOAD CSF and ${ }^{18}$ F-FDG PET features differ from LOAD. CSF biomarker analysis showed comparable levels of $A \beta_{1-42}$ and Tau (both total and phosphorylated) between EOAD and LOAD, although t-Tau levels showed higher levels in the EOAD group. These findings are in line with the previous literature [27-29] and indicate that in younger individuals the neurodegenerative process remains dependent on $A \beta$ pathology, shows a stronger intensity of neurodegeneration and likely progresses more rapidly than what is observed in LOAD individuals. Although the t-Tau levels in our group of EOAD patients remained higher than those 
found in the LOAD group, the differences did not reach significance, and, unfortunately, we are unable to help solving controversies on CSF differences between EOAD and LOAD [27, 28, 30]. ${ }^{18}$ F-FDG PET showed unexpectedly that typical EOAD presents an asymmetric pattern with hypometabolism in the left precuneus (BA7 and BA31) and supramarginal gyrus (BA40), as observed in the description of atypical cases, and with a localization that differs from LOAD. Such findings led us to suppose that the asymmetric localization observed in ${ }^{18} \mathrm{~F}$-FDG PET is not dependent on the clinical presentation of the cases (typical/atypical), but rather on a regional vulnerability of associative areas of the brain, whose involvement might determine the slower/faster evolution observed in $\mathrm{AD}$ cases [30,31].

The precuneus is a medial parietal lobe region with associative functions. It is highly connected to other cortical regions and also receives innervations from subcortical nuclei like the cholinergic basal forebrain [32]. It has also been shown that the precuneus together with other cortical regions (i.e. medial prefrontal and posterior cingulate cortices, hippocampus) act as a hub region of the rest-active default mode network (DMN). This consists of a specific set of brain areas that decrease activity during the performance of a wide range of tasks, and that are active during the period of rest [33]. The different DMN structures are highly interconnected cortical processing networks involved in tasks like memory, vision, hearing and emotions. Early changes of the DMN were recently described and implicated in the pathogenesis of AD symptoms, where reduced activation of the prefrontal and cingulate cortices and the precuneus appear as reliable markers from the early phases of the disease [34]. Interestingly, reduced activity of the precuneus has been associated with AD variants, with nonamnestic presentation, while in this work we show that also in the amnestic presentation of EOAD patients, the precuneus presents with reduced metabolic activity. Such a finding, on the one hand, strengthens the concept of heterogeneity of presentations in $\mathrm{AD}$, but on the other hand, it indicates that the onset and evolution of the neurodegeneration of AD could be dependent specifically on the site or regional cortical vulnerability or on the specific involvement of DMN nodes. Indeed, both the LOAD and EOAD groups in our study showed focal hypometabolism, although in different cortical regions (left precuneus for the EOAD group and right cingulate cortex for the LOAD group, both considered nodes of the DMN). Apparently, each node has its specific vulnerability and, therefore, shows a different age at onset as well as evolution. Of note, such differences in cortical vulnerability could also be independent of the normal aging process. Aging induces changes in the DMN and may have further deleterious effects on cortical connectivity destructuration. Thus, precocious cortical deafferentation, due to abnormal $A \beta$ metabolism or Tau hyperphosphorylation [35], would induce rapid cortical disorganization in regions less involved in memory functions, like the precuneus, and determine the intensity of degeneration as well as the evolution rate (slow/ fast) of cognitive deficits, besides a neuropsychological presentation [34, 36, 37]. Such a notion would also help to solve the controversies about CSF biomarkers, showing that differences between the two groups reside in the intensity of neurodegeneration of cortical hubs. Of course this is a suggestive hypothesis, and studies of larger cohorts of patients are needed to deepen our knowledge.

In conclusion, we found that EOAD patients with a typical amnestic presentation show CSF abnormalities with low $A \beta_{1-42}$ and very high t-Tau levels, though not significantly different from LOAD patients, as well as precuneus hypometabolism. These features are similar to those described in the literature for cases with an atypical presentation, which confirms that EOAD represents a unique clinicopathologic entity. Finally, we suggest that EOAD should be considered as an expression of precocious cortical network hub disorganization. In addition, using CSF biomarkers as a covariate in the SPM analyses, we are also able to evaluate the age factor independently of CSF biomarkers and main cognitive parameters (see the Materials and Methods section). This type of analysis allows demonstrating that 'age at onset of AD' is 
a factor related to a peculiar metabolic phenotype of the disease and suggests that in EOAD patients the cortical metabolism in the left precuneus and supramarginal gyrus should be considered carefully in the evaluation of PET images independently of the expected results based on other factors such as CSF biomarkers. In a recently published study performed on a large cohort of AD subjects, it has been shown that an increased amyloid burden in the brain is related to nonselective cortical dysfunction in $\mathrm{AD}$ (with a great reduction of brain glucose metabolism being detectable in those patients with low $A \beta_{1-42}$ levels in CSF) [38]. A more selective pattern that mainly involves the cingulate cortex was related to high t-Tau and p-Tau values in CSF. All these areas were not detectable in the comparison between EOAD and LOAD, as shown in table 2. As a last aspect, our study shows an age-related reduction in glucose consumption in the right anterior cingulate cortex in the CG's BA24 and BA32 (table 3). Cerebral glucose metabolism is mainly related to glucose consumption in neural cells due to synaptic activity; hence, the reduced glucose consumption observed is consistent with an agerelated, reduced function of BA24 and BA32. Our findings are in agreement with several investigations reporting an age-related reduction in synaptic density or in synaptic count in the human cerebral cortex $[39,40]$, and such reductions have most consistently been reported in the frontal neocortex [41]. A reduced cortical activity in BA24 and BA32 in 065 as compared to U65 subjects could be explained with an age-related impairment in the working memory process, with this structure being actively involved during memory tasks [42].

A significant limitation of our study is the lack of a dedicated neuropsychological evaluation of this domain in the CG; it will be necessary for future studies to include longitudinal assessments of neuropsychological performance in order to investigate an impairment of those areas where a hypometabolism has been found in elderly as compared to young healthy subjects.

\section{Disclosure Statement}

The authors have no conflicts of interest to declare.

\section{References}

$>1$ Tapiola T, Pirttilä T, Mehta PD, Alafuzofff I, Lehtovirta M, Soininen H: Relationship between apoE genotype and CSF beta-amyloid (1-42) and tau in patients with probable and definite Alzheimer's disease. Neurobiol Aging 2000;21:735-740.

-2 Sperling RA, Dickerson BC, Pihlajamaki M, Vannini P, LaViolette PS, Vitolo OV, Hedden T, Becker JA, Rentz DM, Selkoe DJ, Johnson KA: Functional alterations in memory networks in early Alzheimer's disease. Neuromolecular Med 2010;12:27-43.

-3 Vieira RT, Caixeta L, Machado S, Silva AC, Nardi AE, Arias-Carrión 0, Carta MG: Epidemiology of early-onset dementia: a review of the literature. Clin Pract Epidemiol Ment Health 2013;9:88-95.

4 Nelson L, Tabet N: Slowing the progression of Alzheimer's disease; what works? Ageing Res Rev 2015;23(Pt B):193-209.

5 Smits LL, Pijnenburg YA, Koedam EL, van der Vlies AE, Reuling IE, Koene T, Teunissen CE, Scheltens P, van der Flier WM: Early onset Alzheimer's disease is associated with a distinct neuropsychological profile. J Alzheimers Dis 2012;30:101-108.

-6 Koedam EL, Lauffer V, van der Vlies AE, van der Flier WM, Scheltens P, Pijnenburg YA: Early-versus late-onset Alzheimer's disease: more than age alone. J Alzheimers Dis 2010;19:1401-1408.

7 Greicius MD, Geschwind MD, Miller BL: Presenile dementia syndromes: an update on taxonomy and diagnosis. J Neurol Neurosurg Psychiatry 2002;72:691-700.

-8 Balasa M, Sánchez-Valle R, Antonell A, Bosch B, Olives J, Rami L, Castellví M, Molinuevo JL, Lladó A: Usefulness of biomarkers in the diagnosis and prognosis of early-onset cognitive impairment. J Alzheimers Dis 2014;40: 919-927.

-9 Mann DM, Yates PO, Marcyniuk B: Monoaminergic neurotransmitter systems in presenile Alzheimer's disease and in senile dementia of Alzheimer type. Clin Neuropathol 1984;3:199-205. 
10 Castellani RJ, Lee HG, Zhu X, Nunomura A, Perry G, Smith MA: Neuropathology of Alzheimer disease: pathognomonic but not pathogenic. Acta Neuropathol 2006;111:503-509.

11 Mendez MF: Early-onset Alzheimer's disease: nonamnestic subtypes and type 2 AD. Arch Med Res 2012;43: 677-685.

12 Kaiser NC, Melrose RJ, Liu C, Sultzer DL, Jimenez E, Su M, Monserratt L, Mendez MF: Neuropsychological and neuroimaging markers in early versus late-onset Alzheimer's disease. Am J Alzheimers Dis Other Demen 2012;27:520-529.

13 Alberici A, Benussi A, Premi E, Borroni B, Padovani A: Clinical, genetic, and neuroimaging features of Early Onset Alzheimer Disease: the challenges of diagnosis and treatment. Curr Alzheimer Res 2014;11:909-917.

-14 Bouwman FH, Verwey NA, Klein M, Kok A, Blankenstein MA, Sluimer JD, Barkhof F, van der Flier WM, Scheltens P: New research criteria for the diagnosis of Alzheimer's disease applied in a memory clinic population. Dement Geriatr Cogn Disord 2010;30:1-7.

15 Mosconi L: Brain glucose metabolism in the early and specific diagnosis of Alzheimer's disease. FDG-PET studies in MCI and AD. Eur J Nucl Med Mol Imaging 2005;32:486-510.

16 Möller C, Vrenken H, Jiskoot L, Versteeg A, Barkhof F, Scheltens P, van der Flier WM: Different patterns of gray matter atrophy in early- and late-onset Alzheimer's disease. Neurobiol Aging 2013;34:2014-2022.

17 Varma AR, Snowden JS, Lloyd JJ, Talbot PR, Mann DM, Neary D: Evaluation of the NINCDS-ADRDA criteria in the differentiation of Alzheimer's disease and frontotemporal dementia. J Neurol Neurosurg Psychiatry 1999; 66:184-188.

18 Pierantozzi M, Panella M, Palmieri MG, Koch G, Giordano A, Marciani MG, Bernardi G, Stanzione P, Stefani A: Different TMS patterns of intracortical inhibition in early onset Alzheimer dementia and frontotemporal dementia. Clin Neurophysiol 2004;115:2410-2418.

19 Carlesimo GA, Caltagirone C, Gainotti G: The Mental Deterioration Battery: normative data, diagnostic reliability and qualitative analyses of cognitive impairment. The Group for the Standardization of the Mental Deterioration Battery. Eur Neurol 1996;36:378-384.

20 Magni E, Binetti G, Padovani A, Cappa SF, Bianchetti A, Trabucchi M: The Mini-Mental State Examination in Alzheimer's disease and multi-infarct dementia. Int Psychogeriatr 1996;8:127-134.

-21 Caffarra P, Vezzadini G, Dieci F, Zonato F, Venneri A: Rey-Osterrieth complex figure: normative values in an Italian population sample. Neurol Sci 2002;22:443-447.

22 Carlesimo GA, Buccione I, Fadda L, Graceffa A, Mauri M, Lorusso S, Bevilacqua G, Caltagirone C: Standardizzazione di due test di memoria per uso clinico: breve racconto e figura di Rey. Nuova Riv Neurol 2002;12:1-13.

-23 Sancesario GM, Esposito Z, Nuccetelli M, et al: Abeta1-42 detection in CSF of Alzheimer's disease is influenced by temperature: indication of reversible Abeta1-42 aggregation? Exp Neurol 2010;223:371-376.

24 Cistaro A, Valentini MC, Chiò A, et al: Brain hypermetabolism in amyotrophic lateral sclerosis: a FDG PET study in ALS of spinal and bulbar onset. Eur J Nucl Med Mol Imaging 2011;39:251-259.

25 Chiaravalloti A, Pagani M, Cantonetti M, et al: Brain metabolic changes in Hodgkin disease patients following diagnosis and during the disease course: an ${ }^{18}$ F-FDG PET/CT study. Oncol Lett 2015;9:685-690.

-26 Varrone A, Asenbaum S, Vander Borght T, Booij J, Nobili F, et al: EANM procedure guidelines for PET brain imaging using $\left[{ }^{18} \mathrm{~F}\right] \mathrm{FDG}$, version 2. Eur J Nucl Med Mol Imaging 2009;36:2103-2110.

27 Bouwman FH, Schoonenboom NS, Verwey NA, van Elk EJ, Kok A, Blankenstein MA, Scheltens P, van der Flier WM: CSF biomarker levels in early and late onset Alzheimer's disease. Neurobiol Aging 2009;30:1895-1901.

28 Koric L, Felician O, Guedj E, Hubert AM, Mancini J, Boucraut J, Ceccaldi M: Could clinical profile influence CSF biomarkers in early-onset Alzheimer disease? Alzheimer Dis Assoc Disord 2010;24:278-283.

-29 Ossenkoppele R, Zwan MD, Tolboom N, van Assema DM, Adriaanse SF, Kloet RW, Boellaard R, Windhorst AD, Barkhof F, Lammertsma AA, Scheltens P, van der Flier WM, van Berckel BN: Amyloid burden and metabolic function in early-onset Alzheimer's disease: parietal lobe involvement. Brain 2012;135(Pt 7):2115-2125.

30 Fijell AM, McEvoy L, Holland D, Dale AM, Walhovd KB; Alzheimer's Disease Neuroimaging Initiative: What is normal in normal aging? Effects of aging, amyloid and Alzheimer's disease on the cerebral cortex and the hippocampus. Prog Neurobiol 2014;117:20-40.

-31 Karas G, Scheltens P, Rombouts S, van Schijndel R, Klein M, Jones B, van der Flier W, Vrenken H, Barkhof F: Precuneus atrophy in early-onset Alzheimer's disease: a morphometric structural MRI study. Neuroradiology 2007;49:967-976.

-32 Ikonomovic MD, Klunk WE, Abrahamson EE, Wuu J, Mathis CA, Scheff SW, Mufson EJ, DeKosky ST: Precuneus amyloid burden is associated with reduced cholinergic activity in Alzheimer disease. Neurology 2011;77: 39-47.

-33 Snyder AZ, Raichle ME: A brief history of the resting state: the Washington University perspective. Neuroimage 2012;62:902-910.

-34 Jacobs HI, Radua J, Lückmann HC, Sack AT: Meta-analysis of functional network alterations in Alzheimer's disease: toward a network biomarker. Neurosci Biobehav Rev 2013;37:753-765.

-35 Simic G, Babic M, Borovecki F, Hof PR: Early failure of the default-mode network and the pathogenesis of Alzheimer's disease. CNS Neurosci Ther 2014;20:692-698.

-36 Canuet L, Pusil S, López ME, Bajo R, Pineda-Pardo JÁ, Cuesta P, Gálvez G, Gaztelu JM, Lourido D, García-Ribas G, Maestú F: Network disruption and cerebrospinal fluid amyloid-beta and phospho-tau levels in mild cognitive impairment. J Neurosci 2015;35:10325-10330. 
Chiaravalloti et al.: Comparison between Early-Onset and Late-Onset Alzheimer's Disease Patients with Amnestic Presentation: CSF and ${ }^{18}$ F-FDG PET Study

37 Koch G, Belli L, Giudice TL, Lorenzo FD, Sancesario GM, Sorge R, Bernardini S, Martorana A: Frailty among Alzheimer's disease patients. CNS Neurol Disord Drug Targets 2013;12:507-511.

-38 Chiaravalloti A, Martorana A, Koch G, Toniolo S, di Biagio D, di Pietro B, Schillaci O: Functional correlates of $\mathrm{t}$-Tau, $\mathrm{p}$-Tau and $\mathrm{A} \beta_{1-42}$ amyloid cerebrospinal fluid levels in Alzheimer's disease: a ${ }^{18} \mathrm{~F}-\mathrm{FDG}$ PET/CT study. Nucl Med Commun 2015;36:461-468.

-39 Scheibel ME, Lindsay RD, Tomiyasu U, Scheibel AB: Progressive dendritic changes in aging human cortex. Exp Neurol 1975;47:392-403.

40 Liu X, Erikson C, Brun A: Cortical synaptic changes and gliosis in normal aging, Alzheimer's disease and frontal lobe degeneration. Dementia 1996;7:128-134.

41 Terry RD, DeTeresa R, Hansen LA: Neocortical cell counts in normal human adult aging. Ann Neurol 1987;21: 530-539.

42 Lenartowicz A, McIntosh AR: The role of anterior cingulate cortex in working memory is shaped by functional connectivity. J Cogn Neurosci 2005;17:1026-1042. 